\title{
Solid Potential Reference Electrode for Concrete Corrosion Monitoring
}

\author{
Paulo Sérgio Duque de Brito*, Paulo Teixeira Cunha ${ }^{1}$ \\ and Mário Guerreiro Silva Ferreira ${ }^{1}$ \\ C3i - Centro Interdisciplinar de Investigação e Inovação Instituto Politécnico de Portalegre \\ Lugar da Abadessa, Apartado 148, 7301-901 Portalegre, Portugal \\ 'Departamento de Engenharia Cerâmica e do Vidro Universidade de Aveiro \\ Campus Universitário de Santiago, 3810-193 Aveiro, Portugal
}

(Received August 12, 2011; accepted October 4, 2012)

Key words: concrete corrosion, monitoring, reference electrodes

The introduction of sensors in reinforced concrete structures is nowadays the most promising methodology to monitor the corrosion of those structures in real time. The need for reliable, solid and low-cost reference electrodes is a specific need in this type of monitoring. In this work, graphite pseudo-references were studied and prepared with graphite powder immobilized within a cement matrix. The electrodes exhibit stability in saturated calcium hydroxide solutions and concrete specimens aged in environments with sodium chloride for several months. The behaviour of graphite pseudo-references in terms of polarization was studied in saline environments. The results obtained allow us to conclude that the electrodes exhibit stability and do not respond to variations in the concentration of chlorides, showing their possible use in reinforced concrete structures subject to marine environments.

\section{Introduction}

The degradation of reinforced concrete structures is a problem with high economic and environmental impacts. One of the main causes of the degradation of the structures mentioned is the corrosion of the reinforcement steel. As is common knowledge, the steel inside the concrete finds a chemical environment that, being favourable to the phenomenon of iron passivation, confers a high resistance to corrosion to the steel. However, such resistance tends to drastically decrease when the environment exhibits high concentrations of chlorides, or of $\mathrm{CO}_{2}$, namely, marine, industrial, urban, or road environments, leading the steel to a state of active corrosion with the progressive degradation of the concrete structure. The phenomenon of chemical or electrochemical corrosion of the reinforcements mentioned above is visible to the naked eye only in the advanced stages of the process, when the reinforcement is completely depassivated, in

${ }^{*}$ Corresponding author: e-mail: pbrito@estgp.pt 
which the corrosion process leads to the formation of corrosion products of relatively high volume, which will create fissures in the structure, and ferrous runoffs appear at the surface of the concrete. The detection of corrosion problems at this stage is too late for the implementation of control processes of reparation of the structure. Hence, the use of inspection and monitoring techniques that allow for the detection of these phenomena as early as possible is prudent. Given that the degradations are a consequence of the corrosion of the reinforcement steel, it essentially has an electrochemical nature, which points to the convenience of the use of electrochemical techniques for the monitoring of these processes. ${ }^{(1)}$

The measurement of the potential of the reinforcement steel based on reference electrodes and potentiometers of high internal impedance, or measurement of the mixed potential of corrosion, is one of the most simple techniques to apply and also one of the most widely used.(2) Figure 1 shows a schematic representation of the reinforcement iron corrosion process using the Evans diagrams. These diagrams are very useful in the analysis of electrochemical phenomena such as corrosion and, as we shall see later, the phenomena that develop in the electrodes studied in this work. As shown in Fig. 1 , the corrosion potential allows one to assess in which domain the steel is inside the concrete: whether in the immunity area where the domain remains intact, or in the active dissolution area where the corrosion occurs, or in the passivation area where it is protected by the layer of compact oxides/hydroxides impermeable to the oxygen or even in the transpassivation area where it essentially suffers pitting attacks.

On the other hand, the use of other electrochemical techniques to monitor concrete structures, such as linear polarization resistance, or even the application of a cathodic protection system, requires the existence of stable and reliable reference electrodes. ${ }^{(3)}$

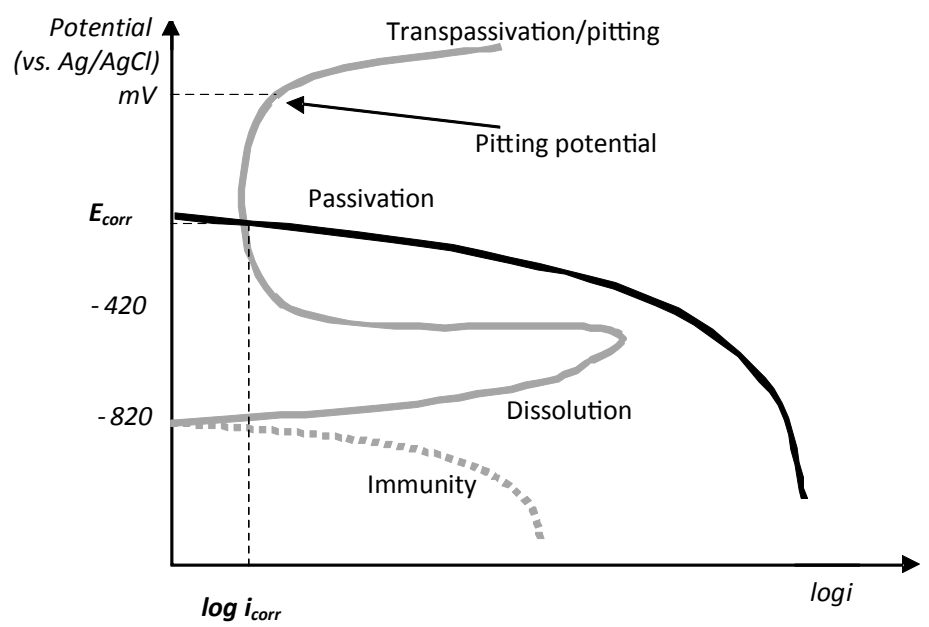

Fig. 1. Schematic representation of an Evans diagram for the corrosive process of the reinforcement iron in the interior of the concrete structure. 
The measurement of the potential can be performed with the aid of an external electrode, in the case that it is an inspection, or of internal electrodes placed in the interior of the structure, in a permanent monitoring perspective of the degradation of the structure. $^{(4)}$ There are several reference electrodes used for external measurement of the potential, of which $\mathrm{Ag} / \mathrm{AgCl}, \mathrm{Cu} / \mathrm{CuSO}_{4}$ and $\mathrm{Mn} / \mathrm{MnO}_{2}$ electrodes ${ }^{(5-6)}$ stand out. These electrodes exhibit several properties that make them good references: a) they exhibit a potential regulated by a reversible balance, which follows the Nernst equation; b) they return to the reversible potential after small polarizations; c) they exhibit a stable value; and d) they are robust. However, permanent use of these electrodes inside the concrete, implying lifetimes of many years, has brought problems due to stability, size and cost issues. Actually, some of the electrodes presenting good electrochemical characteristics have physical limitations when intended to be used for several years inside concrete structures. Some of the electrodes operate in aqueous media, such as $\mathrm{Ag} / \mathrm{AgCl}$ and $\mathrm{Cu} /$ $\mathrm{CuSO}_{4}$, requiring a guarantee of a constant concentration of the electrolyte over time.

In the perspective of the development of electrodes that allow a greater durability at lower cost and with simplicity of construction, different pseudo references have been tested and applied in construction sites, ${ }^{(7)}$ namely, noble metals, graphite and metalmetal oxides (MMOs). ${ }^{(8-12)}$ A pseudo reference does not have, at the start, a reversible reaction that is identifiable as opposed to the real reference electrodes. The behaviour of these electrodes is not predictable by the Nernst equation, but can, in some cases, exhibit a stable behaviour with time. Sometimes, the behaviour of the pseudo references, particularly the metallic ones, can be explained based on a mixed potential of corrosion. Several authors have studied the behaviour of graphite pseudo references, ${ }^{(12-14)}$ not always observing concurrent results in terms of stability and response to environmental variables, such as moisture content, oxygen and chlorides. Note, however, that the number of graphitical materials is high, with different functional groups and porosities, which dictate different behaviours. Nevertheless, in a general way, one attributes to these pseudo references sensitivity to oxygen and moisture and a low sensitivity to the content of chloride ions. Where long-term stability is concerned, results differ.

In this work, the aim was to study the behaviour of graphite pseudo references for application in a monitoring system of concrete structures prepared from graphite powder impregnated within a cement base with the intent to create stable, reliable and longlasting electrodes.

\section{Experimental}

The graphite pseudo references were prepared by mixing different quantities of powdered graphite into a cement mortar (type $32.5 \mathrm{KN}$ Portland), with a cementwater ratio of 0.7 , in a vinyl mould $1 \mathrm{~cm}$ in diameter and $3 \mathrm{~cm}$ in length. As current collectors, copper and stainless steel 304 wires were used. In Table 1, the different types of electrodes studied are shown. We studied different cement/graphite ratios in order to evaluate the effect of dispersion of the graphite in the electrochemical process, particularly the ratio between the anodic and cathodic processes that influence the mixed potential electrode. The electrical resistance of the electrodes is inferior to $1.2 \Omega / \mathrm{cm}$, 
Table 1

Graphite electrodes in cement matrix.

\begin{tabular}{lcc}
\hline Electrode & $\begin{array}{c}\text { Graphite/cement ratio } \\
\text { in mortar }(\mathrm{g} / \mathrm{c})\end{array}$ & Current collector \\
\hline $\mathrm{A}$ & 0.75 & Copper \\
$\mathrm{B}$ & 0.50 & Copper \\
$\mathrm{C}$ & 0.33 & Stainless steel 304 \\
$\mathrm{D}$ & 0.30 & Stainless steel 304 \\
\hline
\end{tabular}

which consubstantiates a high electrical conductivity. In Fig. 2, a photograph of one of the electrodes is shown.

The variations of the potential of the several types of electrode, in relation to a saturated calomel electrode, were determined in saturated calcium hydroxide solutions and inside $\mathrm{C} 20 / 25$ concrete specimens in relation to an internal electrode of $\mathrm{Cu} / \mathrm{CuSO}_{4}$. The specimens used were: a) Type I - precontaminated concrete in the mortar with $\mathrm{CaCl}_{2} 4 \%$ in a mass of cement subject to 48 -h cycles of condensation, at $50^{\circ} \mathrm{C}$, in a salt spray chamber (Corrosionbox 400L Salt Spray Chamber), following a rest in the natural environment of the lab for $96 \mathrm{~h}$; b) Type II - without contamination subject to salt spray cycles using a $\mathrm{NaCl} 3 \%$ solution in water mass at $50^{\circ} \mathrm{C}$ for $96 \mathrm{~h}$ following exposure for $60 \mathrm{~h}$ to the natural environment of the laboratory. The dimensions of the specimens were $50 \times 30 \times 10 \mathrm{~cm}^{3}$ and the specimens were tested for $700 \mathrm{~d}$. A UT60 multimeter with input impedance of $40 \mathrm{M} \Omega$ was used.

Anodic and cathodic polarization curves were made for the several electrodes, in a three-electrode cell in $\mathrm{NaCl}$ aqueous solutions at different concentrations, $\mathrm{pHs}$ and with and without ventilation, at $25^{\circ} \mathrm{C}$ (see Fig. 3). The auxiliary electrode was a $316 \mathrm{~L}$ steel net with an apparent area of $100 \mathrm{~cm}^{2}$. The potential of the working electrode was determined in relation to a $\mathrm{Ag} / \mathrm{AgCl}, \mathrm{KCl} 1 \mathrm{M}$ reference electrode. A Gamry 600 potentiostat connected to a $\mathrm{PC}$ was used. The open circuit potentials (OCPs) were determined and scans were made from the open circuit potential (vs $\mathrm{Ag} / \mathrm{AgCl}$ ) until up to $\pm 400 \mathrm{~V}(\mathrm{vs} \mathrm{Ag} / \mathrm{AgCl})$ at a scanning speed of $5 \mathrm{mV} / \mathrm{s}$.

\section{Results and Discussion}

In Table 2, the OCP values and current of the oxidation-reduction of powdered graphite electrodes supported in a cement mortar in sodium chloride solutions at different concentrations, pHs and oxygen contents are shown. The current results shown in Table 2 were determined on the basis of the polarization curves, as are the ones shown in Fig. 4, following the Tafel procedure. For a better analysis of the results shown in Table 2, the variations of the OCP and current as functions of $\mathrm{pH}$ and chloride concentration are shown in Fig. 5.

The obtained OCP results allow us to verify that: a) there is a decrease in the value of the potential with the increase in the concentration of sodium chloride in the solution; b) there is a decrease in the potential value when the $\mathrm{pH}$ of the solution increases; and c) 


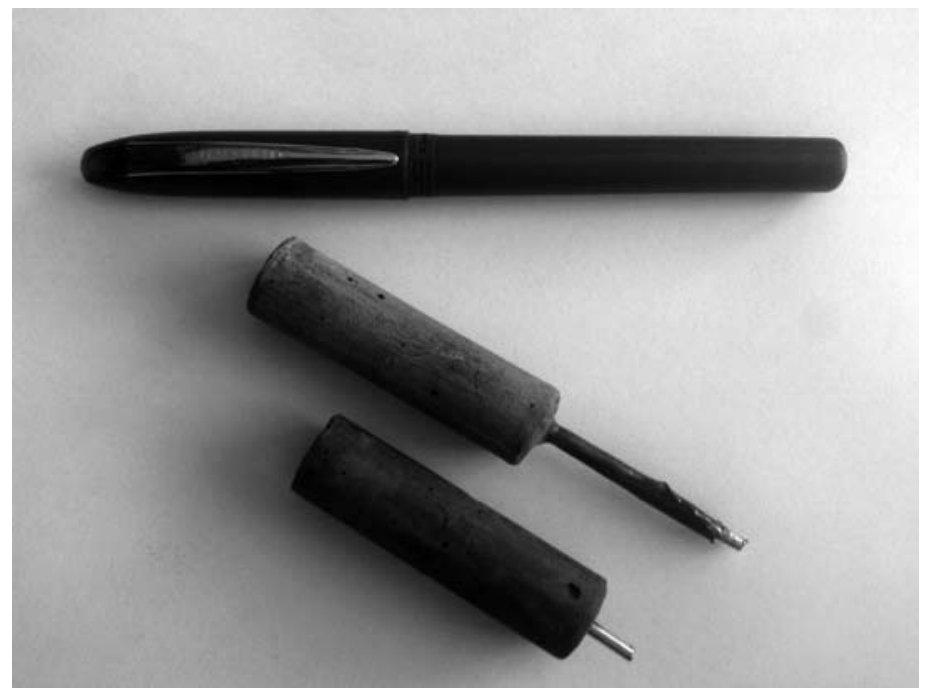

Fig. 2. Photograph of one of the graphite electrodes produced.

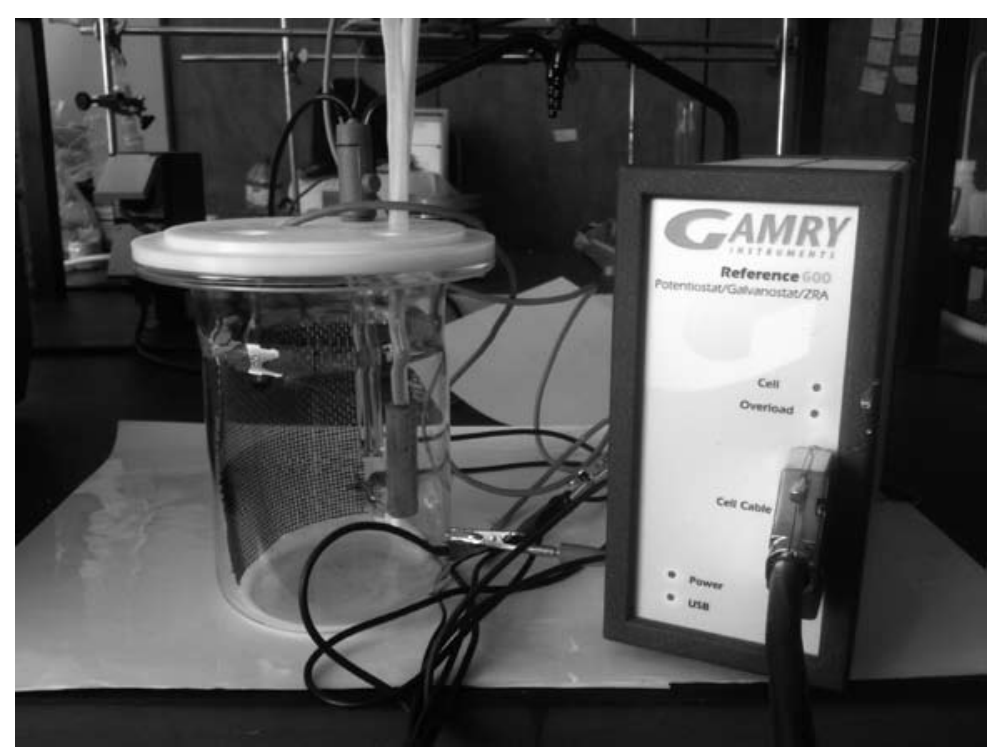

Fig. 3. Photograph of the experimental apparatus for electrochemical tests.

there is a decrease in the potential when the oxygen content in the solution decreases.

Note that the results are consistent with the fact that the OCP is the result of a mixed potential involving the reduction of oxygen, according to the following reaction: 
Table 2

OCP of the D electrode in sodium chloride solutions at different concentrations, $\mathrm{pHs}$, and oxygen contents.

\begin{tabular}{|c|c|c|c|c|c|c|c|c|}
\hline \multirow[t]{2}{*}[\mathrm{Cl}^{-}]{$(\mathrm{M})$} & \multicolumn{4}{|c|}{$\begin{array}{c}\text { OCP }(\mathrm{mV}) \text { vs ENH } \\
\mathrm{pH}\end{array}$} & \multicolumn{4}{|c|}{$\begin{array}{c}I(\mu \mathrm{A}) \\
\mathrm{pH}\end{array}$} \\
\hline & 8 & 10 & 12 & 13 & 8 & 10 & 12 & 13 \\
\hline \multicolumn{9}{|c|}{ Aerated solution } \\
\hline 0.001 & 268 & 291 & 267 & 170 & 64.5 & 67.3 & 76.7 & 63.4 \\
\hline 0.01 & 270 & 272 & 252 & 160 & 68.6 & 67.2 & 68.3 & 58.6 \\
\hline 0.1 & 202 & 221 & 202 & 140 & 62.2 & 62.8 & 60.0 & 73.6 \\
\hline \multicolumn{9}{|c|}{ Deaerated solution } \\
\hline 0.001 & 160 & 157 & 180 & 150 & 49.6 & 52.3 & 53.4 & 52.9 \\
\hline 0.01 & 190 & 186 & 182 & 155 & 51.4 & 51.7 & 53.0 & 50.4 \\
\hline 0.1 & 172 & 171 & 162 & 140 & 52.4 & 51.9 & 51.5 & 49.9 \\
\hline
\end{tabular}

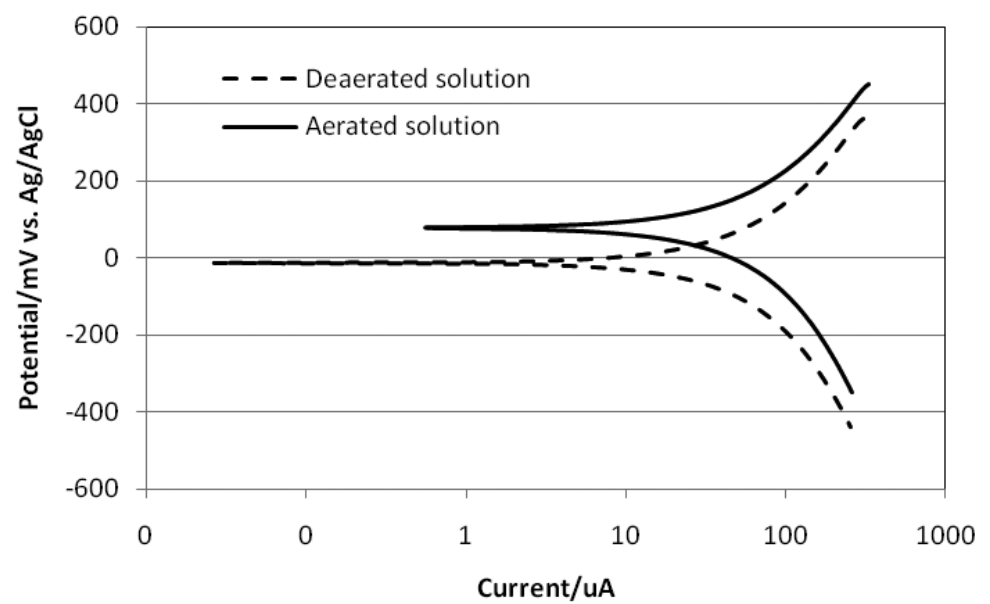

Fig. 4. Polarization curves of the $\mathrm{D}$ electrode in aerated and deaerated solution of $0.01 \mathrm{M} \mathrm{NaCl}$ at $\mathrm{pH} 12$.

$$
\begin{gathered}
\mathrm{O}_{2}+2 \mathrm{H}_{2} \mathrm{O}+4 \mathrm{e}^{-} \rightarrow 4 \mathrm{OH}^{-} \\
E_{\mathrm{O}_{2} / \mathrm{OH}^{-}}=0.40 \mathrm{~V}
\end{gathered}
$$

and a cathodic process, which would be the semireaction of oxidation of iron oxides, present in the bulk cement, according, eventually, to the following reaction:

$$
\begin{gathered}
2 \mathrm{Fe}(\mathrm{OH})_{2}+2 \mathrm{OH}^{-} \rightarrow \mathrm{Fe}_{2} \mathrm{O}_{3}+3 \mathrm{H}_{2} \mathrm{O}+2 \mathrm{e}^{-} \\
E_{\mathrm{EF}_{2} \mathrm{O}_{3} / \mathrm{Fe}(\mathrm{OH})_{2}}=-0.860 \mathrm{~V}
\end{gathered}
$$




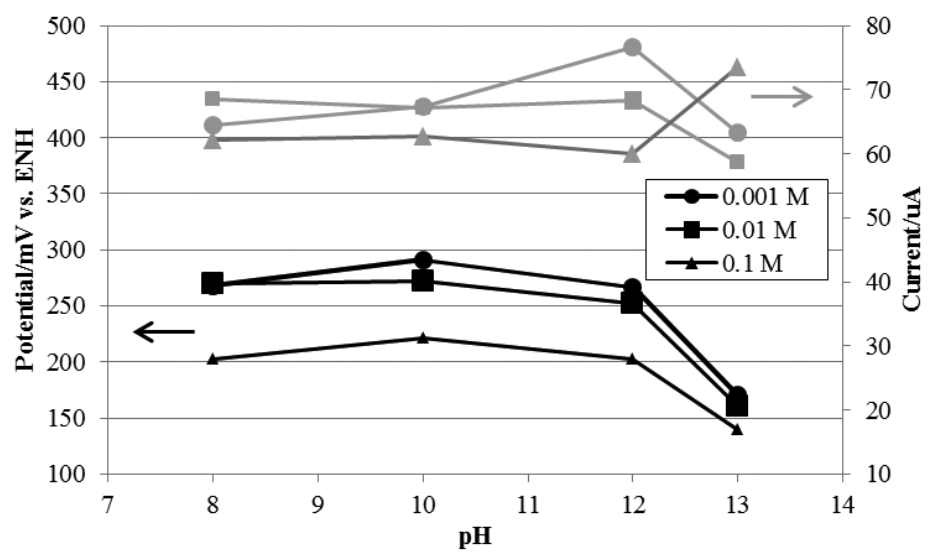

(a)

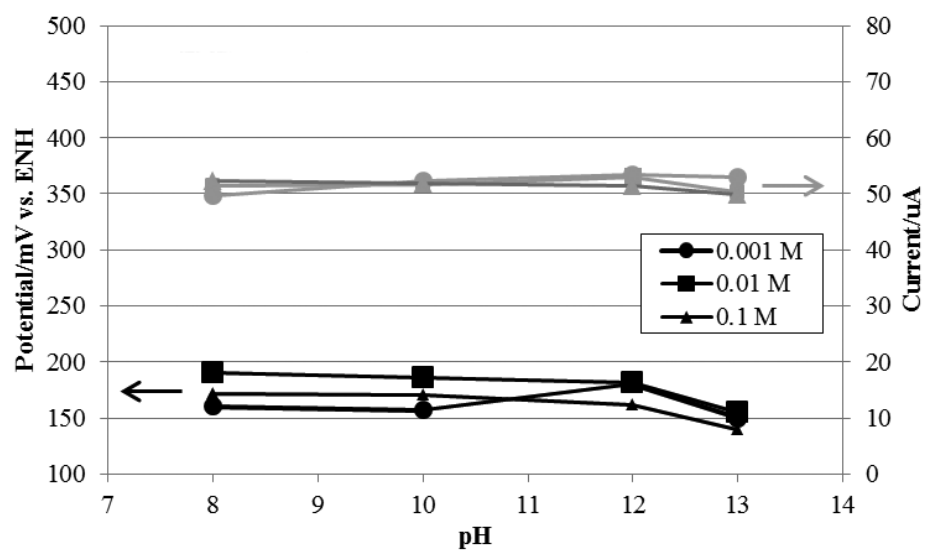

(b)

Fig. 5. Variations of OCP and current as functions of $\mathrm{pH}$ and chloride concentration: (a) aerated solution and (b) deaerated solution.

The acceptance of the hypothesis of the occurrence of this reaction results in the analysis of the reduction potentials of the main substances present in the system under scrutiny (electrode and electrolyte), namely, water, sodium chloride and the main constituents of cement (calcium oxides, silicium, magnesium, aluminium and iron).

If the process that occurs in the electrode is an electrochemical process, it might be characterized by a mixed process (see Fig. 1), with its potential between the potentials of the two semireactions of reduction (1) and oxidation (2).

Through the analysis of the results of the current exhibited, in Table 2, it is observable that they follow, generically, the same variation of the OCP: a) decrease in the current with the increase in the concentration of sodium chloride in the solution; b) decrease in 
the current when the $\mathrm{pH}$ of the solution increases; and c) decrease in the current when the oxygen content in the solution decreases.

This way, the relation between OCP and current is a result of a mixed process; their variations can be explained on the basis of the variation of the kinetics of the processes involved. In Fig. 6, a schematic representation of Evans diagrams for the process under study is presented. The decrease in oxygen in the solution, due to the nitrogen deaeration bubble [Fig. 6(a)], or decrease in oxygen solubility after the increase in the chloride concentration [Fig. 6(c)], leads to an increase in the concentration polarization of the oxygen reduction semireaction. The increase in the concentration polarization of the oxygen reduction semireaction infers a decreasing OCP and the current of the system. On the other hand, the increase in the $\mathrm{pH}$ leads to a translation of the cathodic curve to more negative values, a result of the decrease in the balancing potential of the oxygen reduction [see Fig. 6(b)].

In terms of the application of this type of electrode to monitoring systems of the degradation of reinforced concrete structures, ${ }^{(1)}$ one must mention that the results obtained have the following implications. In the first place, the OCP and the current are not direct functions of the concentration of chloride ions. Variations of the OCP and current with the chloride concentration are due to the decrease in the solubility of oxygen

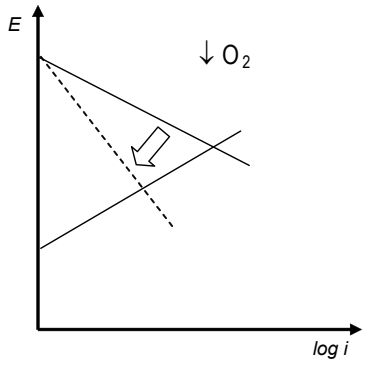

(a)

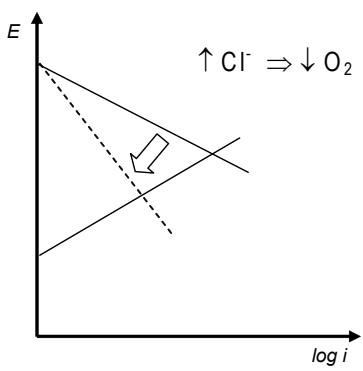

(c)

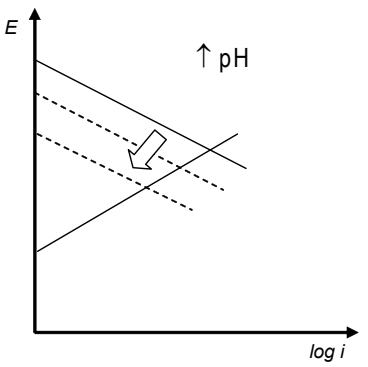

(b)

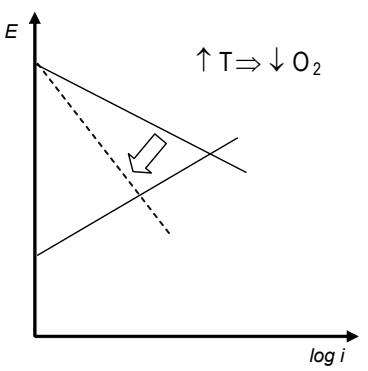

(d)

Fig. 6. Schematic representation of Evans diagrams for the electrochemical process. 
with the increase in the content of chlorides in solution. Nevertheless, the decrease in the OCP and current of the electrode with the increase in the content of chloride ions leads, with time, to the contamination of a structure, and the consequent increase in the concentration of chlorides inside it and a decrease in the reference value, which may give false indications about the domain where the reinforcement is, mainly in the active/ passive limit. Thus, for the use of this type of electrode in monitoring situations where the contamination of the structure with chloride ions is predictable, one should take this effect into account by considering a high value for the limit of OCP for a process of active dissolution.

On the other hand, and inversely, the increase in the OCP when one decreases the $\mathrm{pH}$ of the environment makes the assessment safer when one is in a degradation area by carbonatation of the structure. In this case, the decrease in the $\mathrm{pH}$ of the structure will make the OCP of the electrode increase, which is an alert of the active/passive transition.

Concerning the assessment of the stability of the electrodes, tests were carried out with time in aqueous saturated calcium hydroxide solutions and in concrete specimens contaminated with sodium chloride. In Fig. 7, the results obtained with the different electrodes in saturated calcium hydroxide solutions are shown. The first assessment is that one observes in all electrodes a certain oscillatory behaviour. Such behaviour is directly related to temperature variations of the environment. In fact, an observation of the temperature variations throughout the test, such as the one shown in Fig. 8 for the $\mathrm{C}$ electrode in saturated calcium hydroxide solution, allows one to clearly realise the dependence of the potential on the temperature: increases in temperature lead to a decrease in the potential and vice-versa. This dependence is due to the fact that with the increase in temperature, there is a decrease in the solubility of the oxygen leading to a rise in the polarization of the semireaction of reduction of the oxygen with a decrease in the OCP [see Fig. 6(d)].

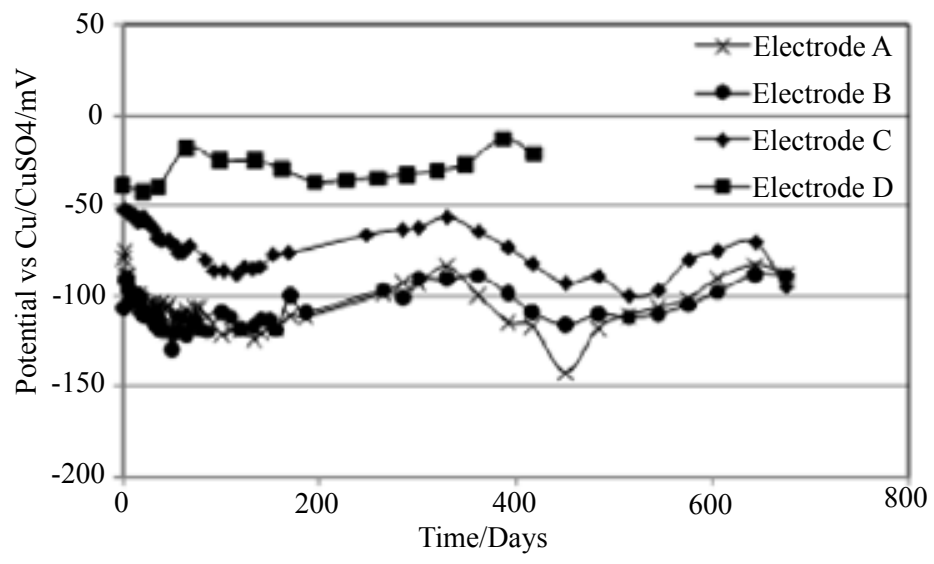

Fig. 7. Variation of OCP of electrodes in solutions of saturated $\mathrm{Ca}(\mathrm{OH})_{2}$. 
The results of the variation of the OCP of the electrodes in an aqueous calcium hydroxide solution (see Fig. 8) also allow one to verify that there is a tendency for OCP to be more negative as you increase the graphite/cement ratio (see Table 1). This can be explained on the basis of the same model of mixed potentials we have been using. In fact, the electrodes with a higher percentage of graphite exhibit less porosity since the graphite contributes to its clogging. Less porosity implies a smaller area for the reaction and consequent polarization of the cathodic process of reduction of oxygen with a decrease in the OCP (see Fig. 6).

Figure 9 shows a comparison of the electrodes studied and other different electrodes in measuring the steel reinforcement Ecorr, namely, pure graphite electrode (also a pseudo reference electrode) and a $\mathrm{Cu} / \mathrm{CuSO}_{4}$ reference electrode. It can be observed that the behaviours of the electrodes inside the concrete, under very aggressive conditions of ageing, are very similar. In a general way, all the electrodes have similar oscillations and similar to the reference electrode $\mathrm{Cu} / \mathrm{CuSO}_{4}$. On the other hand, the OCP of the studied electrodes and all the other electrodes oscillates around an average value without an increasing or decreasing tendency, a very positive result in the perspective of the use of this type of electrode in monitoring systems of reinforced concrete structures. In this type of system, the systematic dislocation of the potential of a pseudo-reference to more positive or negative values can lead to wrong assessments, particularly in the definition of domains of passivity or of active dissolution (see Fig. 1).

On the other hand, one observes that there is no significant variation between the values of the OCP of the electrode in the two experimental ageing situations studied, allowing again to conclude the noninterference of chloride ions in the process that is occurring in the electrode. Thus, one projects very favourably the use of this type of electrode in monitoring systems of reinforced concrete structures, for instance, in marine environments.

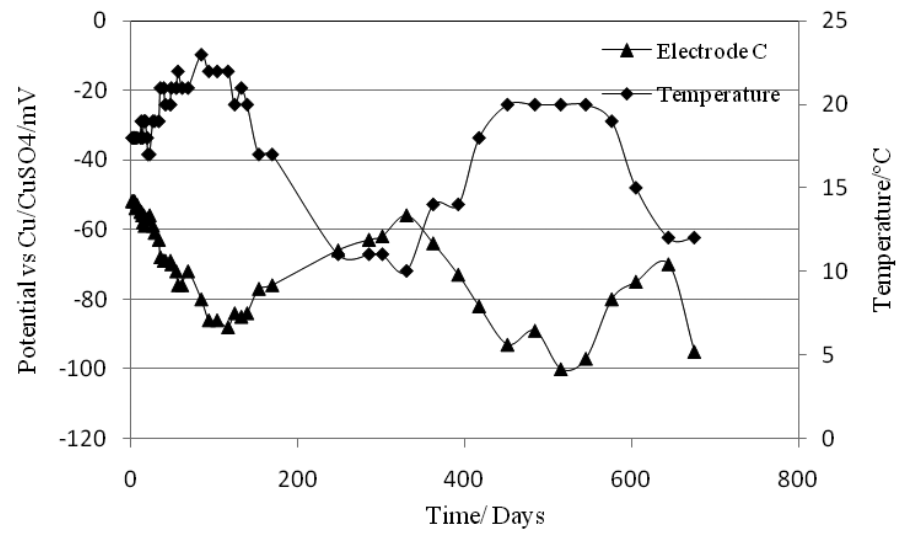

Fig. 8. Variation of OCP of electrodes and temperature in solution of saturated $\mathrm{Ca}(\mathrm{OH})_{2}$. 


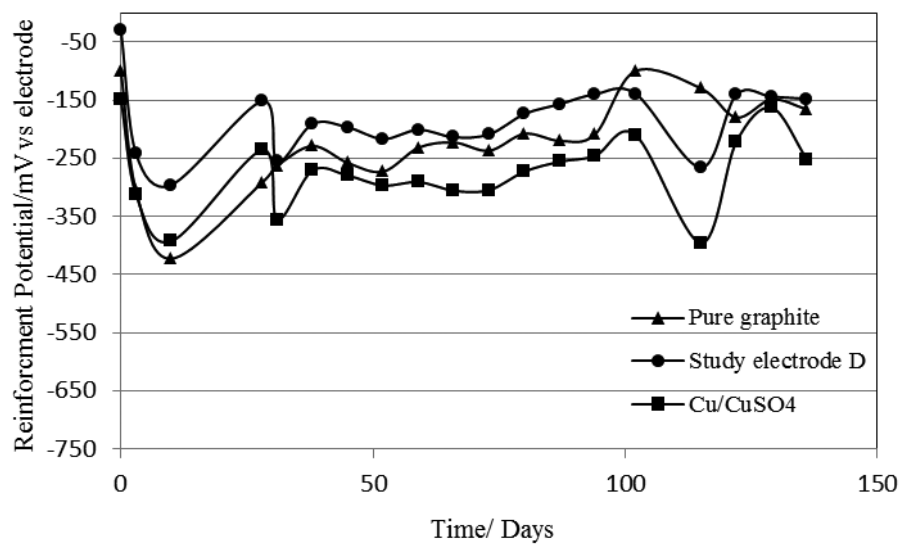

(a)

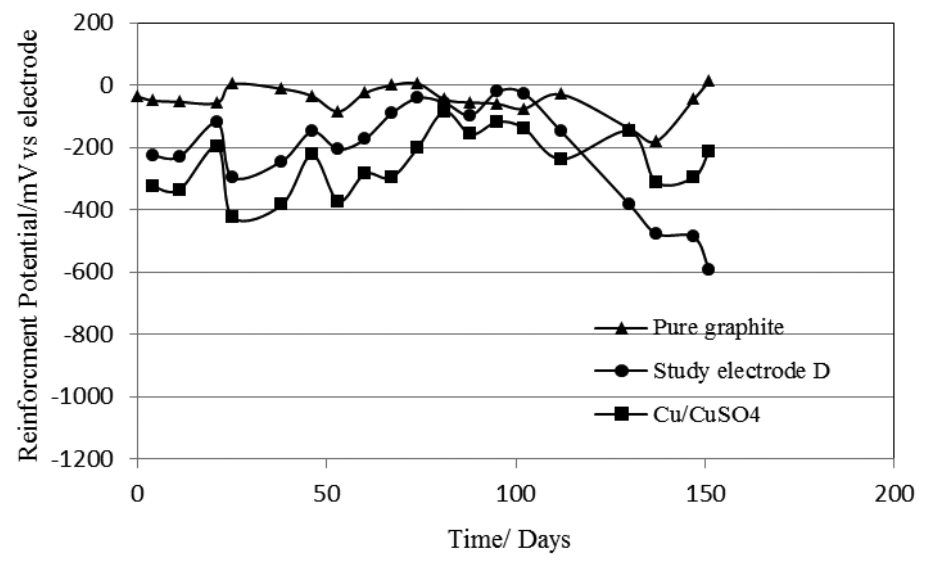

(b)

Fig. 9. Comparation of the variation of the potential of the electrodes $\mathrm{D}$ with pury graphite and $\mathrm{Cu} / \mathrm{CuSO}_{4}$ reference electrodes: (a) inside the specimens contaminated with $\mathrm{CaCl}_{2}$ (Type I) and (b) inside the specimens without any initial contamination (Type II).

\section{Conclusions}

In this work, graphite pseudo references were prepared with immobilized graphite powder in a cement matrix and studied, leading to the following conclusions:

a) The electrodes exhibited stability in solutions of saturated calcium hydroxide and aged concrete specimens in environments with sodium chloride for several months.

b) The electrodes in aqueous solution and inside the concrete exhibit a behaviour characteristic of a mixed potential where the cathodic semireaction is the reaction of the oxygen. 
c) The electrodes present themselves as very promising for application in monitoring systems of concrete structures subject to contaminations with chloride ions.

\section{References}

1 F. P. Glasser, J. Marchand and E. Samson: Cem. Concr. Res. 38 (2008) 226.

2 H. Song and V. Saraswathy: Int. J. Electrochem. Sci. 2 (2007) 1.

3 P. S. D. Brito, L. F. Rodrigues, M. P. Cunha, C. A. C. Sequeira and D. M. F. Santos: Proc. EUROCORR2007, Freiburg im Breisgau, Germany, 9th to 13th of September of 2007 (2007).

4 Standard Test Method for Corrosion Potentials of Uncoated Reinforcing Steel in Concrete, ASTM C876 (ASTM, West Conshohocken, PA, 1991).

5 H. Dolli, S. Muralidharan and N. S. Rengaswamy: Bull. Electrochem. 19 (2003) 1.

6 M. Montemor, J. Alves, A. Simões, J. Fernandes, Z. Lourenço, A. Costa, A. Appleton and M. Ferreira: Cem. Concr. Compos. 28 (2006) 233.

7 F. Ansuini and J. Dimond: NACE Corrosion (2001) Paper No. 01296.

8 H. C. Schell, D. G. Manning and F. Pianca: Transp. Res. Rec. 1211 (1989) 60.

9 S. Muralidharan, T. Ha, J. Bae, Y. Ha, H. Lee and D. Kim: Measurement 40 (2007) 600.

10 S. Muralidharan, V. Saraswathy, A. Madhavamayandi, K. Thangavel and N. Palaniswamy: Electrochim. Acta 53 (2008) 7248.

11 G. Duffó and S. Farina: Constr. Build. Mater. 23 (2009) 2746.

12 G. Duffó, S. Farina and C. Giordano: Electrochim. Acta 54 (2009) 1010.

13 S. Muralidharan, T. Haa, J. Baea, Y. Haa, H. Lee, K. Park and D. Kim: Sens. Actuators, B 113 (2006) 187.

14 S. Muralidharan, T. Ha, J. Bae, Y. Ha, H. Lee, K. Park and D. Kim: Mater. Lett. 60 (2006) 651. 